\title{
Effect of homocysteine on the histological structure of femur in young male albino rats and the possible protective role of folic acid
}

Rania A. Zidan and Heba M. Elnegris*

*Correspondence: heba31076@yahoo.com

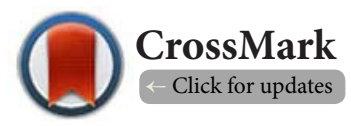

Department of Histology and Cell Biology, Faculty of Medicine, Zagazig University, Egypt.

\begin{abstract}
Introduction: Homocysteine (HCY) is an amino acid that is formed as an intermediate during the metabolism of methionine. The role of hyperhomocysteinemia in the pathogenesis of osteoporosis has been considered a focal point.

Aim of the work: Is to investigate the structural changes that occur in the bone and epiphyseal plate of femur in young male albino rats after being treated with oral HCY and the possible protective role of folic acid.

Materials and methods: Thirty six young male albino rats were used in this experiment. They were equally divided into three group. The control group, $\mathrm{HCY}$ treated group (group II) received $0.6 \mathrm{mg} \mathrm{HCY} / \mathrm{g}$ b.w/day for 6 weeks and protected group (group III) received both HCY and folic acid $(2 \mathrm{mg} / \mathrm{kg}$ ) by oral gavages for 6 weeks. At the end of experiment, the femurs of the animals were prepared for both light (hematoxylin and eosin, mallory trichrome stains and osteoprotegerin immunoreaction) and transmission electron microscopic examinations. Cortical and trabecular bone thickness were assessed using the image analyzer, in addition to counting the number of osteoclasts.
\end{abstract}

Results: HCY treated group showed significant reduction of cortical bone thickness of femur diaphysis with multiple cavity formation as well as a significant reduction in the trabecular bone thickness of distal metaphysis as compared with the control group. Additionally; the cancellous bone trabeculae were also separated by wide bone marrow rich in fat cells associated with a reduction in osteoprotegerin immunoexpression. The distal epiphyseal plate showed a lack of the orderly chondrocytes columns arrangement. Regarding the protected group, bone architecture was maintained so that the cortical and trabecular bone had nearly normal appearance in comparison with the control group. Ultrastructurally, osteocytes showed marked degenerative changes and were surrounded by irregular collagenous fibrils while the osteoclasts were increased as proved statistically.

Conclusion: Hyperhomocysteinemia induced profound histological changes in the epiphyseal plate, trabecular and cortical bone of femur in young rats. Folic acid could have a protective role against these alterations.

Keywords: Homocysteine, femur, folic acid, growing rats

\section{Introduction}

Osteoporosis is a major health problem that is characterized by low bone mineral density, deterioration of bone microarchitecture and an increased risk of fracture [1].

Osteoporotic fractures are associated with increased level of morbidity and mortality and with substantial economic costs $[2,3]$.

It has been hypothesized that the metabolism of homocysteine is involved in osteoporosis [4]. Homocystinuria, a rare autosomal recessive disease characterized by markedly 
Zidan et al. Journal of Histology \& Histopathology 2015,

elevated levels of plasma homocysteine, has several clinical manifestations involving the eyes, the vasculature, and the central nervous system. The presence of homocystinuria is associated with the early onset of generalized osteoporosis $[5,6]$. The underlying pathophysiological mechanism for the occurrence of early osteoporosis in patients who have homocystinuria is not completely understood [7].

Several studies confirmed an association between homocysteine and bone mineral density in postmenopausal women [8,9], in patients with Crohn's disease [10], primary billiary cirrhosis [11], and hyperparathyroidism [12]. A high circulating homocysteine concentration has also been mentioned as an independent risk factor for several chronic conditions, including cardiovascular and Alzheimer disease [13]. It has been proved that the administration of homocysteine caused osteopenia in newborn rats [14]. Whereas, other studies failed to confirm such an association [15].

Homocysteine (HCY) is a sulfur-containing amino acid formed in the metabolic pathway between methionine and cysteine [16]. Elevated levels of homocysteine known as hyperhomocysteinemia (HHCY) are associated with various bone abnormalities, such as osteopenia and osteoporosis $[17,18]$. The thiol groups in Hcy undergo auto-oxidation, thus triggering oxidative stress. Methionine is condensed with ATP to form S-adenosylmethionine, the universal methyl donor in transmethylation reactions and the direct precursor of $\mathrm{HCY}$ in vivo [19].

Folate, vitamin $\mathrm{B}_{6}$ and vitamin $\mathrm{B}_{12}$ are important enzymatic cofactors in the synthesis of methionine from homocysteine (Hcy), and an elevation of Hcy can be caused by insufficiency of folate, vitamin $B_{6}$ or vitamin $B_{12}[\mathbf{2 0 , 2 1 ]}$.

Numerous studies have linked high circulating Hcy levels and low concentrations of folate or vitamin $B_{12}$ with increased risk of low bone mineral density (BMD) in non-diabetic subjects $[22,23]$.

Supplementation with vitamin $B_{12}$ and folate has recently been shown to decrease fracture risk in stroke patients [24].

Folic acid (FA) is a naturally occurring dietary component [25]. A lack of dietary folic acid leads to a folate deficiency [26].

Folic acid is essential to numerous body functions ranging from nucleotide biosynthesis to the remethylation of homocysteine $[\mathbf{2 7}, \mathbf{2 8}]$. Children and adults both require folic acid in order to produce healthy red blood cells and prevent anemia. Folic acid can be used to treat Alzheimer's disease, depression, and certain types of cancer [29].

Previous data indicated a higher bone turnover (resorption and formation) leading to decreased bone mineral density (BMD) among individuals with high Hcy levels. A high bone turnover may lead to lower BMD and is also a risk factor for fracture [30].

Osteoclasts are specialized cells that resorb bone, whereas osteoblasts are cells that synthesize new bone. The RANK ligand (RANKL), a protein expressed by the osteoblasts, plays an important role in osteoclast formation, function, and survival through its interaction with RANK on the osteoclast [31]. Osteoprotegerin (OPG), a natural inhibitor of RANKL, interferes with RANKL and RANK association and thereby regulates osteoclast activity and resorption in the bone $[32,33]$.

Despite this considerable evidence that identifies homocysteine as a risk factor for osteoporosis, the molecular mechanisms of how bone remodeling is hampered during hyperhomocysteinemia still remain ambiguous. The aim of the present work is to investigate the structural changes that occur in the bone and epiphyseal plate of femur in young male albino rats after being treated with oral $\mathrm{HCY}$ and the possible protective role of folic acid.

\section{Materials and methods \\ Experimental animals}

Thirty six young male albino rats (aged 3 weeks, weighing 50-60gm at the beginning of experiment) were housed in stainless steel cages at Animal House, Faculty of Medicine, Zagazig University at room temperature, fed standard balanced diet and allowed water ad libitum. The experiment was performed in accordance with the "Guide for the Care and Use of Laboratory Animals" [34]. The experimental protocol was approved by the Ethical Committee of Zagazig University.

\section{Chemicals}

\section{Homocysteine (HCY)}

Was obtained from Sigma-Aldrich, USA. The drug was dissolved in distilled water as a vehicle.

\section{Folic acid}

Was obtained from El Nasr Pharmaceutical Chemicals Co. And was dissolved in normal saline to give a suspension.

\section{Groups}

Rats were classified into three equal groups (12 animals each).

\section{Group I (Control)}

Rats were further subdivided into three equal subgroups.

\section{Subgroup IA (negative control group)}

Rats were gavaged with $1 \mathrm{ml}$ of distilled water once daily for 6 weeks.

\section{Subgroup IB (saline positive control group)}

Rats were gavaged with $1 \mathrm{ml}$ of normal saline ssolution of $0.90 \% \mathrm{w} / \mathrm{v}$ of $\mathrm{NaCl}$, isotonic saline (the solvent of folic acid) once daily for 6weeks [35].

\section{Subgroup IC (folic acid positive control group)}

Rats were gavaged with folic acid at a dose of $2 \mathrm{mg} / \mathrm{kg}$ dissolved in $1 \mathrm{ml}$ of normal saline for 6weeks [35].

\section{Group II (homocysteine treated group)}

In which rats received daily Hcys at a dose of $0.6 \mathrm{mg} / \mathrm{kg} \mathrm{b.wt}$. 
dissolved in $1 \mathrm{ml}$ distilled water [36] for 6 weeks through oral gavage [37].

\section{Group III: (homocysteine+folic acid group) (protected group)}

The animals in this group received concomitant administration of homocysteine at the same dose and duration as group II plus folic acid at the same dose and duration as group IC.

At the end of experiment, rats of all studied groups were anesthetized with $35 \mathrm{mg} / \mathrm{kg}$ body weight sodium pentobarbital intraperitoneally [38].

\section{Biochemical study}

Blood samples were collected to undergo estimation of serum homocysteine by enzyme-linked immuno sorbent assay (ELISA) test.

With the use of a commercial enzyme-linked immunosorbent assay (ELISA kit) (Automated Chemiluminescent System, AUS: $180^{\circledR}$, Bayer HealthCarc). Total HCY concentration was determined after protein-bound $\mathrm{HCY}$ was converted to free $\mathrm{HCY}$, which was then enzymatically converted to S-adenosyl$\mathrm{L}-\mathrm{HCY}(\mathrm{SAH})$ by S-adenosylhomocysteine hydrolase enzyme. The enzyme is specific for the L-form of homocysteine, which is the only form present in the blood.

\section{Histological study}

Specimen preparation for light microscope examination

The right femurs were carefully dissected free of soft tissue. The distal part of each bone (including the diaphysis with distal metaphysis were obtained using a sharp blade) was immediately fixed in $10 \%$ neutral buffered formaldehyde for 2 days. After fixation, preparation of decalcified specimens was performed using the chelating agent ethylene diamine tetra acetic acid (EDTA) in the form of its disodium salt (5.5 $\mathrm{g}$ ethylene diamine tetra acetic acid in $90 \mathrm{ml}$ distilled water and $10 \mathrm{ml}$ formaldehyde 37-40\%). Decalcification was carried out for 3 weeks, during this time the decalcifying solution was changed every day [39]. The decalcified specimens were dehydrated and processed to form paraffin blocks. Serial coronal sections ( 6 um thick) parallel to the long axis of the femur and extending from one-third to one-half the thickness of each bone were prepared and stained with hematoxylin and eosin (H\&E) and Mallory trichrome stains [39].

The immunohistochemical staining for localization of osteoprotegerin protein was carried out by means of the avidin biotin-peroxidase complex method following the manufacturer's instructions. The slides were incubated with mouse monoclonal anti-OPG antibody 1:250, (MAb 8051, R\&D Systems, Abingdon, UK) for $1 \mathrm{~h}$, washed and incubated for 30 min with antimouse biotin-conjugated secondary antibody $(30 \mu \mathrm{l} / 2 \mathrm{ml}$ of casein solution diluted 1:50) (Vector Laboratories, Peterborough, UK). Slides were washed and developed using $A B C$ Elite kit (Vector Laboratories), followed by diaminobenzidine (DAB) and a 20 sec counterstain with haematoxylin. Negative control sections were incubated with PBS instead of the primary antibody [40].

Positive reaction appeared as brownish granules mainly in the cytoplasm of cells of osteoblastic cell lineage and sometimes areas of the trabecular surface [41]. Positive reaction was also detected in maturative/hypertrophic chondrocytes, and early osteocytes [42].

Specimen preparation for electron microscope examination Small pieces from shaft of femur were immediately fixed in $2.5 \%$ glutaraldehyde buffered with $0.1 \mathrm{M}$ phosphate buffer at $\mathrm{pH} 7.4$ for 2 hours at $4^{\circ} \mathrm{C}$ and then washed with phosphate buffer, postfixed in $1 \%$ osmium tetraoxide in the same buffer for one hour at $4^{\circ} \mathrm{C}$. The postfixed specimens were decalcified by EDTA solution in buffer for 3 successive days at $4^{\circ} \mathrm{C}$. Then the specimens were washed in phosphate buffer and were dehydrated with ascending grades of ethanol. They were put in propylene oxide for 30 minutes at room temperature, impregnated in a mixture of propylene oxide and resin (1:1) for 24 hours and in a pure resin for another 24 hours. Then, the specimens were embedded in Embed-812 resin in BEEM capsules at $60^{\circ} \mathrm{C}$ for 24 hours [43].

Ultra-thin sections were obtained using Leica ultra cut UCT and stained with uranyl acetate and lead citrate [43] and were examined with JEOL JEM 1010 electron microscope in Electron Microscope Research Laboratory (EMRL) of Histology and Cell Biology Department, Faculty of Medicine, Zagazig University.

\section{Morphometric and statistical study}

The following parameters 'of the femur bone were quantified:

1. Outer cortical bone thickness $(\mu \mathrm{m})$ of diaphysis: (mean width of outer cortical bone). This was measured by drawing a perpendicular line from just beneath the periosteum to the endosteum. Cortical bone thickness or width $(\mu \mathrm{m})$ were determined at five levels $(0.5 \mathrm{~mm}$ apart), starting $0.2 \mathrm{~mm}$ below the lowest point of the growth plate [44].

2. Trabecular bone thickness $(\mu \mathrm{m})$ : the thickness of trabeculae in cancellous bone of distal metaphysis were measured at their midpoint away from their branching areas [45].

For estimation of outer cortical bone thickness and trabecular bone thickness, the mean values of ten non overlapping fields (at magnification $\times 200$ ) from each of five different sections at different femur levels of 4 animals from each group were taken.

3. The number of osteoclasts was estimated/high power field (hpf). Osteoclasts were counted in ten random high power non overlopping fields in five sections obtained from each animal of 4 animals in each group.

The standard deviation was calculated and statistical analysis was carried out. The image analyzer computer system Leica Qwin 500 (Leica Ltd, Cambridge, UK) at the Image Analyzing Unit of the Pathology Department, Faculty of Dentistry, Cairo 
Zidan et al. Journal of Histology \& Histopathology 2015,

http://www.hoajonline.com/journals/pdf/2055-091X-2-16.pdf

doi: 10.7243/2055-091X-2-16

University (Egypt), was used. Using SPSS statistical program version 17.

Data were evaluated by using the one-way analysis of variance test. The probability values $(P)$ less than 0.05 was considered significant and highly significant when the $P$ values were less than 0.001 .

\section{Results}

\section{Light microscopic observations}

The light and electron microscopic examinations of subgroups $\mathrm{la}, \mathrm{lb}$ and $\mathrm{lc}$ of the control group revealed similar morphological results; hence, we chose the results of subgroup la (negative control) to represent the control group.

\section{Observations of H\&E stained sections}

The distal metaphysis of control femur showed a network of irregular bone trabeculae and bone marrow spaces between them. The osteocytes surrounded by their lacunae were present in the bone matrix (Figure 1A).

The distal epiphyseal plate of control femur showed the four distinct zones of the epiphyseal growth plate with regular chondrocyte column arrangement. The growth plate showed columns of resting zone, proliferative zone, the prominent hypertrophic zone and the calcification zone, (Figure 1B). The cortical bone of femur diaphysis of the same group showed many haversian systems with well observed haversian canals and osteocytes in their lacunae. Basophilic osteoblasts on

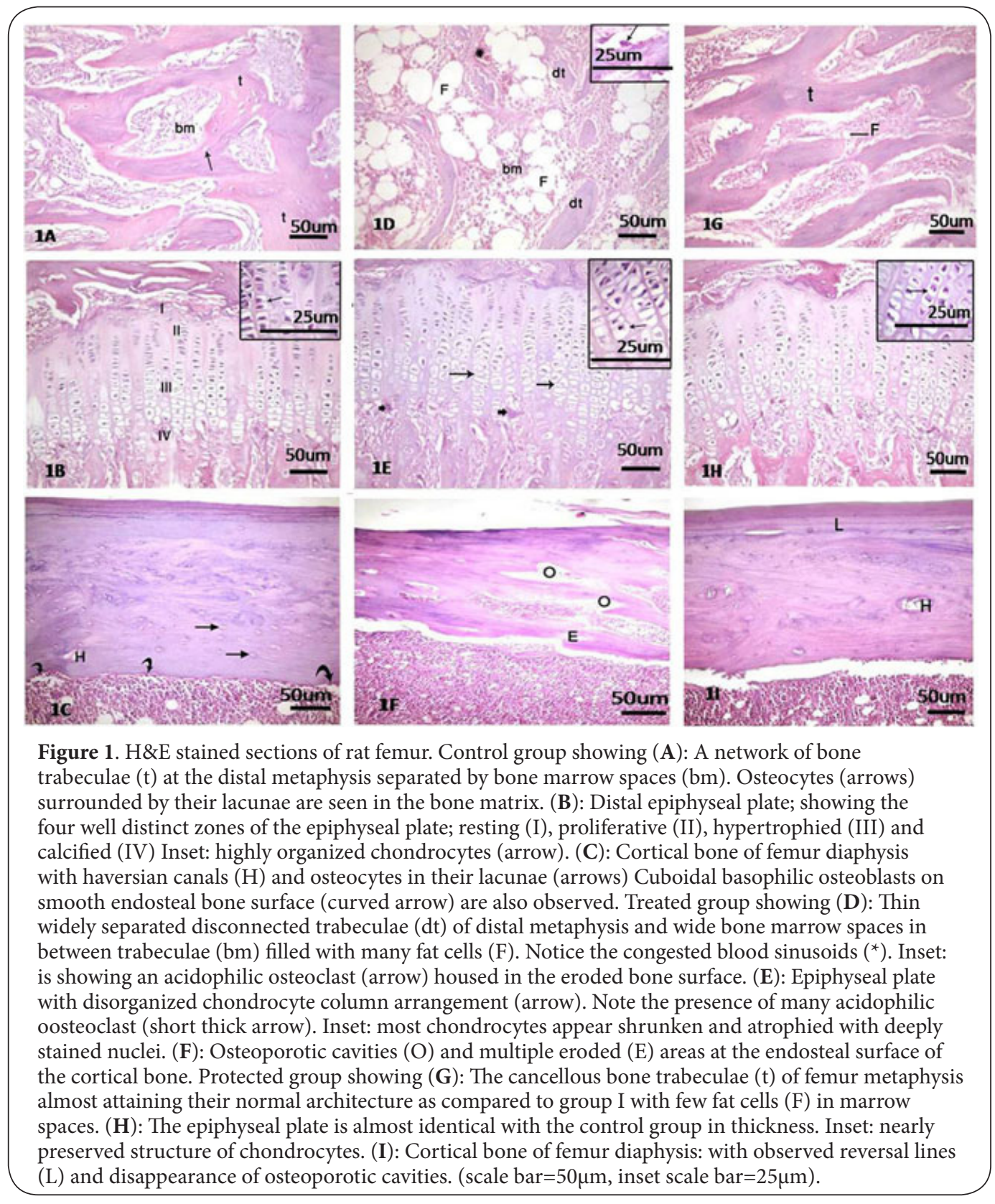


smooth endosteal bone surface were also noticed (Figure 1C).

Examination of H\&E stained sections at the distal metaphysis of treated femur revealed thin widely separated disconnected trabeculae, wide bone marrow spaces filled with many fat cells and congested blood sinusoids (Figure 1D). Osteoclasts housed in the eroded bone surface were also seen (inset, Figure 1D).

Examination of $\mathrm{H} \& \mathrm{E}$ epiphyseal plate sections obtained from homocysteine treated rats revealed disorganized chondrocyte column arrangement, chondrocytes appeared shrunken atrophied with deeply stained nuclei. Also, many acidophilic osteoclasts were noticed (Figure 1E). As regard, sections of the femur diaphysis of this group; osteoprotic cavities (Resorption cavities) were observed in the cortical bone. Moreover, the endosteal surface of the cortical bone appeared irregularly eroded (Figure 1F).

Examination of H\&E stained sections at the distal metaphysis of femur of protected group showed bone trabeculae almost attaining their normal architecture as compared with group I. Scattered adipocytes in marrow spaces were noticed (Figure 1G). Whereas, the epiphyseal plate was almost identical with the control group in thickness and chondrocytes attain nearly preserved structure (Figure $\mathbf{1 H}$ ). The femur diaphysis of this group showed cortical bone with disappearance of osteoporotic cavities and appearance of many reversal lines (Figure 11).

\section{Observations of mallory trichrome stained sections}

Ttrabecular bone of control group showed high content of blue collagen fibers (Figure 2A). As regard the epiphyseal plate; the highly organized chondrocytes were embedded in an abundant bluish extracellular matrix (Figure 2B). Whereas; Cortical bone of femur diaphysis had many regularly arranged blue stained collagen fibers (Figure $\mathbf{2 C}$ ). Mallory trichrome stained sections of treated group showed; few collagen fibers in the trabecular bone that appeared widely separated by
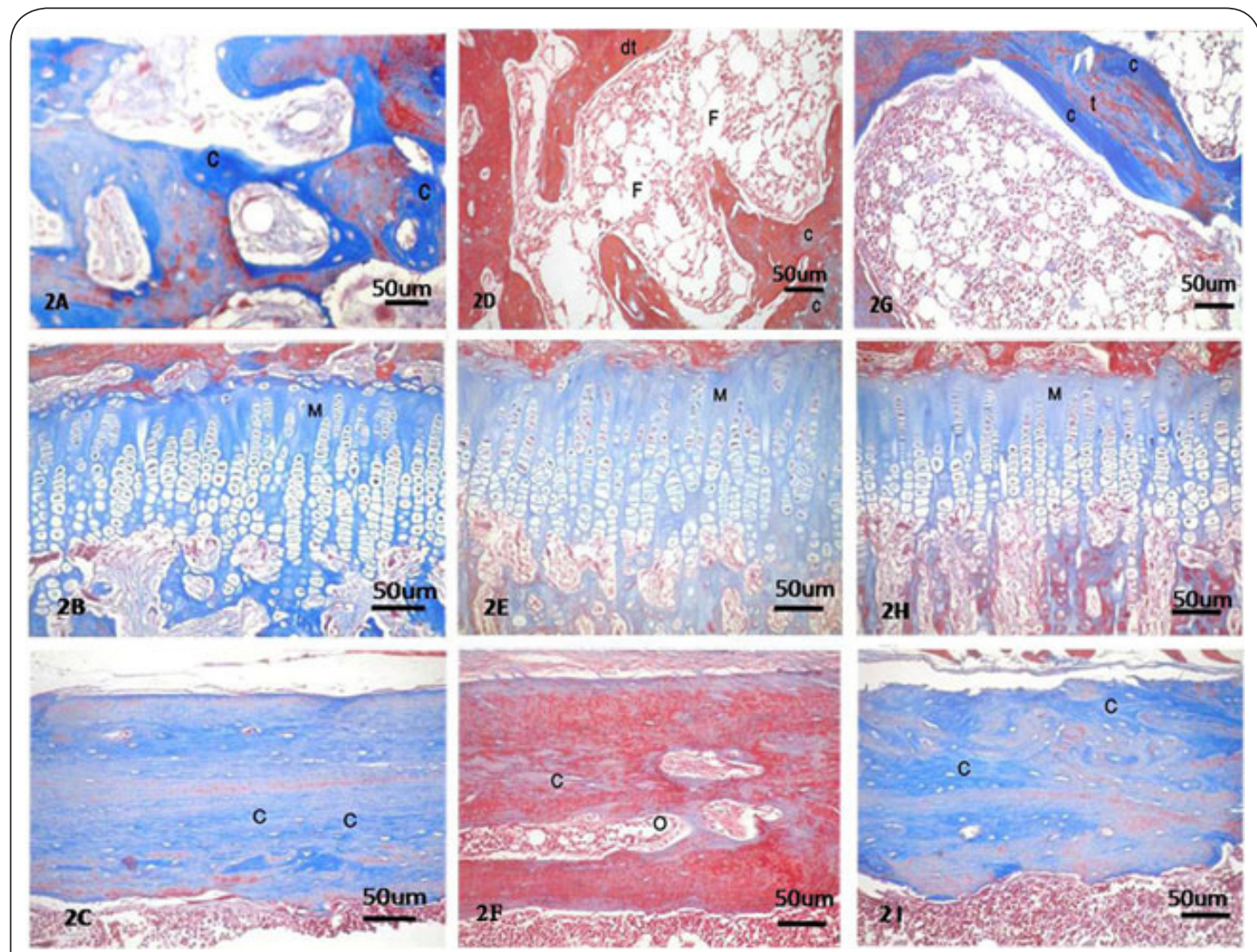

Figure 2. Mallory trichrome stained sections of rat femur. Control group showing. (A): High content of collagen fibers (C) in bone trabeculae of distal metaphysis. (B): Distal epiphyseal plate showing an abundant bluish extracellular matrix (M). (C): Cortical bone of femur diaphysis with many regularly arranged blue stained collagen fibers (C). Treated group showing. (D): Few collagen fibers (C) in the trabecular bone (dt) that appeared widely separated by bone marrow rich in fat cells (F). (E): Extracellular matrix (M) of epiphyseal plate has a weak staining affinity and appeared faint basophilic. (F): Cortical bone with osteoporotic cavities $(\mathrm{O})$, and few blue-stained collagen fibers $(\mathrm{C})$. Note: Non homogenous matrix. Protected group (as compared with control group) showing. (G): Nearly normal content and distribution of collagen fibers $(\mathrm{C})$ in the trabecular bone $(\mathrm{t})$. $(\mathbf{H})$ : Eepiphseal plate matrix $(\mathrm{M})$ with a little reduced staining affinity in comparison with control group. (I): Cortical bone with nearly normal content and distribution of bluestained collagen fibers $(\mathrm{C})$ with no cavity formation. (scale bar $=50 \mu \mathrm{m})$. 
Zidan et al. Journal of Histology \& Histopathology 2015,

bone marrow rich in fat cells (Figure 2D). The epiphyseal plate extracellular matrix had weak staining affinity so it appeared faint basophilic (Figure 2E). Femur diaphysis showed cortical bone with osteoporotic cavities, and few blue-stained collagen fibers. Note. Non homogenous matrix (Figure 2F).

Mallory trichrome stained sections of protected group retained about normal content and distribution of collagen fibers in the trabecular bone in comparison with control group (Figure 2G). The epiphyseal plate matrix showed a little reduced staining affinity in comparison with control group (Figure 2H). Whereas, the cortical bone showed nearly normal content and distribution of blue-stained collagen fibers with no cavity formation (Figure 2I).

\section{Osteoprotegerin immunohistochemistry}

Control group of distal femur metaphysic revealed; osteoprotegerin positive expression in the cytoplasm of most osteoblasts of endosteum. Some osteoprotegerin expression is also observed on the trabecular bone surface (Figure 3A). Examination of distal epiphyseal plate showed most hypertrophic chondrocytes and cartilage-bone interfaces are osteoprotegerin positive (Figure 3B). Whereas, cortical bone of diaphysis of the same group showed that most osteocytes were osteoprotegerin negative while few osteocytes were osteoprotegerin positive (Figure 3C).

Examination of osteoprotegrin stained sections of treated group showed trabecular bone having weak osteoprotegerin

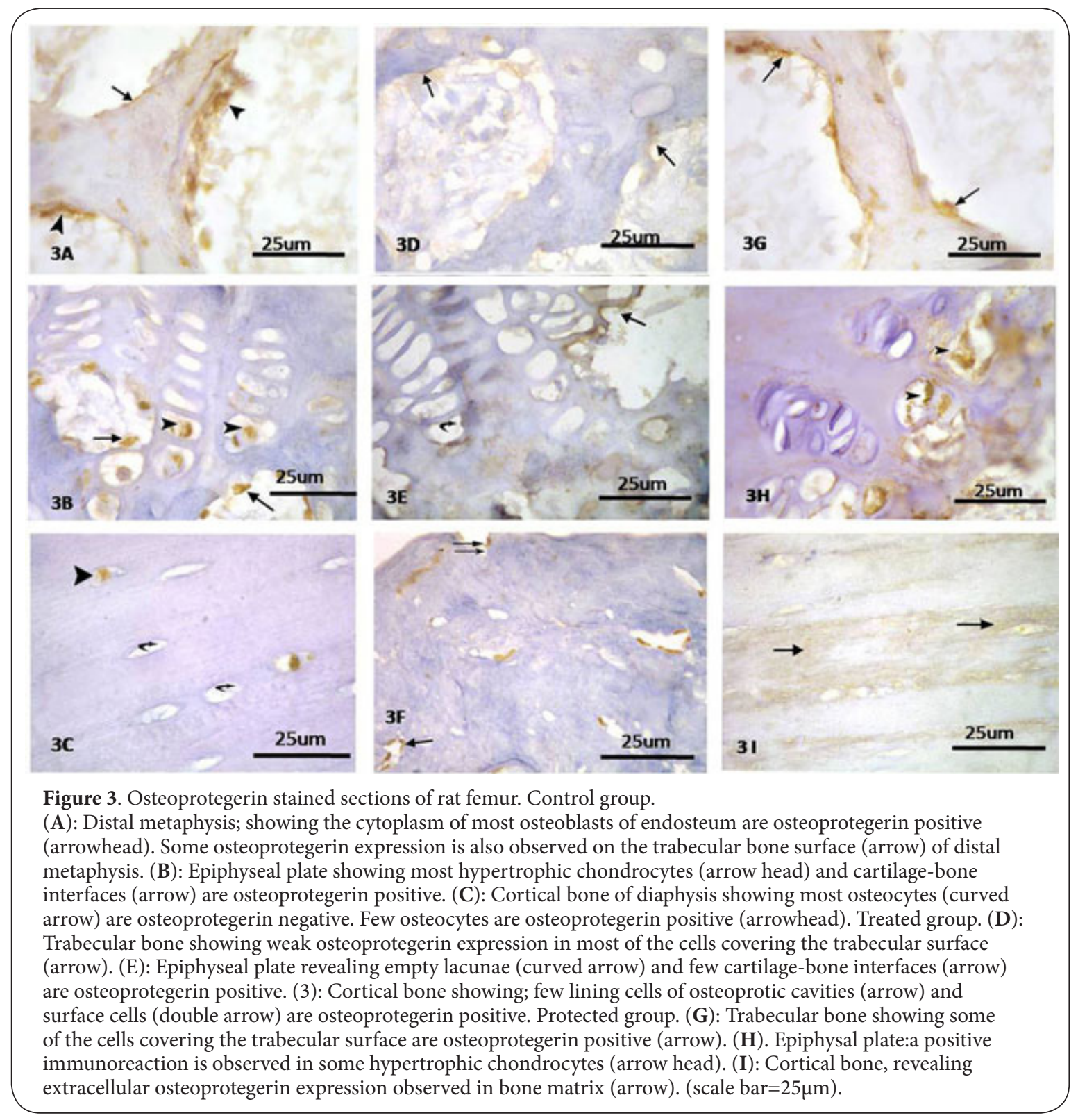


expression in most of the cells covering the trabecular surface (Figure 3D). Examination of epiphyseal plate sections revealed empty lacunae with negative expression of osteoprotegerin whereas few cartilage-bone interfaces were osteoprotegerin positive (Figure $3 \mathrm{E}$ ). As regard sections at femur diaphysis, lining cells of osteoprotic cavities were osteoprotegerin positive (Figure 3F).

Examination of osteoprotegrin stained sections of protected group: showed some of the cells covering the trabecular surface were osteoprotegerin positive (Figure 3G). The epiphysal plate sections of the same group showed a positive immunoreaction observed in some hypertrophic chondrocytes (Figure 3H). Whereas; cortical bone revealed extracellular osteoprotegerin expression observed in bone matrix (Figure 3I).

\section{Electron microscopic results}

Considering examination of ultrathin sections from cortical bone of femur diaphysis of control rats revealed osteoprogenitor cells on bone surface, they contained euchromatic indented nuclei. The osteoblasts were present on the surface side by side, each cell showed many rough endoplasmic reticulum, and euochromatic nucleus with periphral heterochromatin (Figure 4A).

In treated group; osteocytes had irregular nuclei. They were surrounded by many irregular collagen fibrils (Figure 4B). The osteoclasts had irregular nuclei and many membrane bound vacuoles of different sizes. The cells were surrounded with row of osteoblasts within their osteoid product (Figure 4C). In protected group; osteocytes showed oval nuclei and were surrounded by few collagen fibrils in regular lamellae (Figure 4D).

\section{Biochemical results}

There was no significant difference between the biochemical results of group IA, group IB and IC.

There was a significant increase in the levels of serum homocysteine in treated group in comparison with the control group. On the other hand, the protected group showed a significant decrease in homocysteine level when compared with treated group. There was no significant change between the protected group and the control group (Table 1, Figure 5A).

\section{Morphometric results}

There was no significant difference between the morphometric results of group IA, group IB and IC.

The mean cortical and trabecular bone thickness in group II (treated group) presented a significant decrease, $(p<0.05)$ in comparison with the control group. both parameters showed a significant increase when comparing group III with group II (Table 2, Figures 5B and 5C). As regard the number of osteoclasts, there was a highly significant increase in treated group in comparison with the control group. whereas; there was a highly significant reduction in the number of osteoclasts $(\mathrm{P}<0.001)$ in protected group (III) as compared to group (II) (Table 2, Figure 5D).

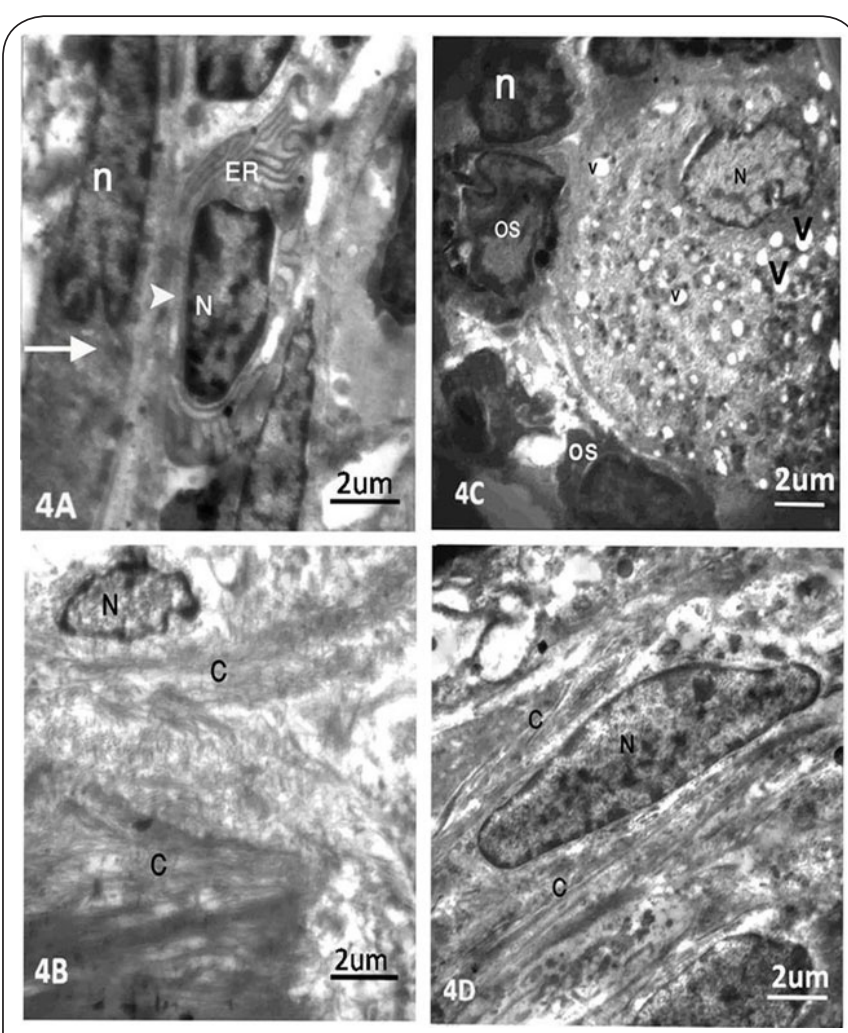

Figure 4. Electron micrographs of ultrathin sections of femur cortical bone (A) control group showing an osteoprogenitor cell (arrow) with euchromatic indented nucleus (n). An osteoblast (arrow head) is also seen having euchromatic nucleus $(\mathrm{N})$ with peripheral heterochromatin and many rough endolasmic reticulum (ER). Treated group (B): Showing an osteocyt with irregular nucleus $(\mathrm{N})$ containing condensed peripheral chromatin, and surrounded with many irregular collagen fibrils (C). (C): Showing an osteoclast with irregular nucleus (N). The cytoplasm contains many membrane bound-vacuoles (v) of different sizes. A row of osteoblasts, (OS) with heterochromatic nuclei (n) surrounding themselves within their osteoid product are also seen. (D): protected group showing an osteocyte with an oval nucleus (N). It is surrounded by few collagenous fibrils $(\mathrm{C})$ in regular lamellae. (Scale bar $=2 \mu \mathrm{m}$ ).

\section{Discussion}

Recent reports have indicated a higher risk of fractures among men and women with high levels of serum homocysteine (HCY) [46]. The cause of moderate hyperhomocysteinemia among adults is mainly by folate or vitamin $B_{12}$ deficiency [47].

However, the mechanistic role of Hcy in osteoporosis is still unknown.

Regarding, the present histomorphometric results $\mathrm{HCY}$ treated group showed a significant reduction of cortical bone thickness with multiple cavity formation as well as a significant reduction in the trabecular bone thickness when compared with that of control rats of group I.

Previous researchers [48] have described osteoporosis as a syndrome of excessive skeletal fragility that results from both the loss of trabecular bone mass and trabecular bone connectivity. 
Zidan et al. Journal of Histology \& Histopathology 2015,

Regarding the epiphyseal plate of HCy treated rats of the present study showed abnormal chondrocyte column cavity, shrunken atrophied chondrocytes with deeply stained nuclei.
The extracellular matrix had weak staining affinity.

The observed results were in accordance with previous researcher findings [1] who demonstrated that homocysteine

Table 1. Mean values of serum homocysteine $(\mu \mathrm{mol} / \mathrm{l})$ in different groups.

\begin{tabular}{l|lllll}
\hline & \multicolumn{3}{c}{ Mean \pm SD } \\
\cline { 2 - 5 } & Group IA & Group IB & Group IC & Group II (HCY treated) & Group III (HCY+folic acid) (protected) \\
\hline Serum homocysteine $(\mu \mathrm{mol} / \mathrm{l})$ & $6.4 \pm 2.36$ & $5.9 \pm 1.2^{\mathrm{n}}$ & $6.3 \pm 1.25^{\mathrm{n}}$ & $11.5 \pm 3.23^{\mathrm{a}}$ & $7.2 \pm 2.26^{\mathrm{b}}$ \\
\hline
\end{tabular}

${ }^{\mathrm{n}}$ non significant as compared with group IA

asignificant as compared with group IA

${ }^{b}$ significant as compared with group II

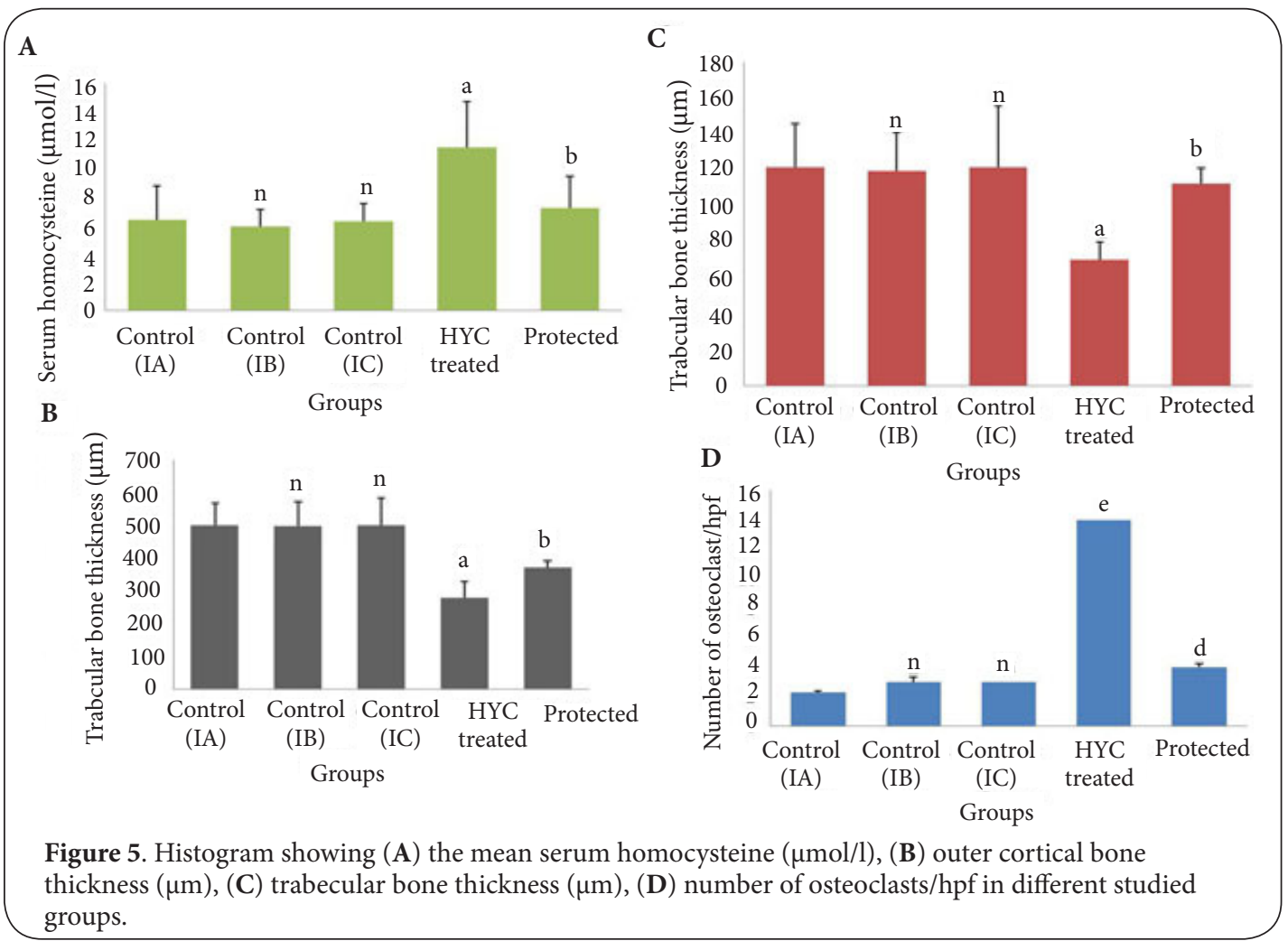

Table 2. Showing the mean outer cortical bone thickness, the mean bone trabecular thickness and the number of osteoclasts/hpf in different groups.

\begin{tabular}{l|lllll}
\hline & \multicolumn{3}{c}{ Mean \pm SD } \\
\cline { 2 - 5 } & Group IA & Group IB & Group IC & Group II (HCY treated) & Group III (HCY+folic acid) (protected) \\
\hline $\begin{array}{l}\text { Outer cortical bone } \\
\text { thickness }(\mu \mathrm{m})\end{array}$ & $499.98 \pm 67.86$ & $498 \pm 75.7^{\mathrm{n}}$ & $501 \pm 83.2^{\mathrm{n}}$ & $279.42 \pm 48.87^{\mathrm{a}}$ & $370.47 \pm 20.75^{\mathrm{b}}$ \\
$\begin{array}{l}\text { trabecular bone } \\
\text { thickness }(\mu \mathrm{m})\end{array}$ & $121.43 \pm 24.1$ & $119.3 \pm 21.3^{\mathrm{n}}$ & $121.4 \pm 34.2^{\mathrm{n}}$ & $70.13 \pm 9.85^{\mathrm{a}}$ & $112.52 \pm 8.4^{\mathrm{b}}$ \\
number of osteoclasts/hpf & $2 \pm 0.1$ & $3 \pm 0.37^{\mathrm{n}}$ & $3 \pm 0.32^{\mathrm{n}}$ & $14 \pm 0.26^{\mathrm{c}}$ & $4 \pm 0.27^{\mathrm{d}}$ \\
\hline
\end{tabular}

${ }^{\mathrm{n}}$ non significant as compared with group IA

${ }^{\text {a }}$ significant as compared with group IA

${ }^{b}$ significant as compared with group II

chighly significant as compared with group IA

dhighly significant as compared with group II 
promoted growth in hypophysectomized rats, a finding, associated with increased thickness of epiphyseal plate.

In addition, other investigators [49] stated that $\mathrm{HCY}$ induced endoplasmic reticulum stress and reduced the secretion and expression of extracellular superoxide dismutase leading to an increase in the production of extracellular reactive oxygen species in vascular smooth muscle cells, leading to increased oxidative stress in the vascular wall $[50,51]$.

In the present study, there was an accumulation of fat cells in the bone marrow of group II, Whereas, the protected group showed a decrease in marrow fat accumulation with the use of folic acid. Previous researchers [52] had reported an inverse relationship between fat and bone volume. This inverse relationship has been documented in bone obtained from animal models with high levels of marrow fat infiltration, such as osteoporosis and senescence-accelerated mouse. The mechanism suggested is through shifting of mesenchymal stem cells into fat cells at the expense of osteoblasts [53].

In the current work, osteoclasts of the treated group exhibited an increase in number as proved statitistically with subsequent bone erosions. Coinciding with these results, clinical studies have shown that adding homocysteine to chick-bud mesenchymal micromass culture caused matrix disorganization, decreased the ability of matrix to support mineralization, increased alkaline phosphatase activity, and abnormalities in collagen cross link formation [54]. Inhibition of collagen cross-linking [55], disturbance of osteoblast function [56], and increased osteoclast activity [57], were also observed in hyperhomocysteinemia.

Osteoprotegerin (OPG), is a member of the tumor necrosis factor receptor gene superfamily [58].

Osteoprotegerin (OPG) is secreted by stromal and osteoblastic lineage cells and inhibits osteoclastogenesis by preventing the interaction of receptor activator of nuclear factor-KB ligand (RANKL) with receptor activator of nuclear factor-KB (RANK) [41].

Ablation of OPG by targeted gene deletion in mice leads to early onset osteoporosis, demonstrating for the first time a critical requirement for endogenous OPG in the maintenance of normal postnatal bone mass and skeletal architecture [59].

In the current study, positive immunohistochemical expression of osteoprotegerin protein in control animals appeared mainly in the cytoplasm of the osteogenic cells and osteoblasts lining the trabecular surface, whereas epiphyseal plates showed positive reaction in maturative/hypertrophic chondrocytes. Most osteocytes of cortical bone appeared negative for osteoprotegerin. The distribution $f$ OPG was previously demonstrated by previous studies [42].

In treated animals of the current work; the trabecular bone showed weak osteoprotegerin expression in most of the cells covering the trabecular surface. Whereas, negative expression of osteoprotegerin was demonstrated in maturative/ hypertrophic chondrocytes of epiphyseal plate while treated cortical bone showed positive expression of OPG in few lining cells of osteoprotic cavities.

Similar observations were detected by previous studies [42] who also observed an extracellular immunolocalization of osteoprotegerin in the cement lines. The presence of osteoprotegerin in these site-specific areas of the trabecular bone matrix could be related to its protective action against the resorbing activity of osteoclasts.

An additional role for OPG in regulating remodeling within the cortical shafts of long bones and within bones of the skull was recorded in OPG-deficient mice [59].

It was found that osteoprotegerin administration inhibited trabecular bone loss and maintained the internal trabecular bone structure and volume in osteoprotegerin deficient mice [60].

In addition, osteoprotegerin administration in mice resulted in a decrease in the number of ostcoclasts together with absence of the ruffled border denoting reduced activity. The positive effect of osteoprotegerin on bone was most probably related to its antiosteoclastogenic capacity [61].

With reference to rats treated with $\mathrm{HCY}$ in the current study, electron microscopic examination revealed many degenerative changes in osteoblasts and osteocytes in the form of irregular nuclei with condensation of their chromatin. The matrix appears highly affected and its fibrils were irregularly arranged. On the other hand, the osteoclasts became more active, their cytoplasm contained many membrane-bound vesicles of various sizes that represent many lysosomes or ruffled border cut in many planes. Therefore, the osteoclasts were more active while osteoblasts and osteocytes were degenerated; reflecting that the bone resorption was more than bone formation with an inaccurate bone remdeling.

Previous experimental data have suggested that high HCY levels affected both osteoclasts and osteoblasts. It was suggested a dysbalance between osteoblasts and osteoclasts in favor of osteoclasts as a major mechanism for HCY-induced bone loss and reduced bone quality in vivo $[4,6]$.

The ultrastructural results of the current work also showed that $\mathrm{HCY}$ treatment resulted in an irregular deposition of collagen fibrils in the extracellular compartment. This could be attributed to disruption of collagen cross-links with other agents which prevent the orderly arrangement of the extracellular matrix. The abnormal deposition of collagen in the extracellular matrix may lead to abnormal cell-matrix interactions [54].

In our study, rats of group III (protected with folic acid) had shown significant lower levels of homocysteine, histologically, these animals were protected from bone loss as compared with treated rats. However, it is not clear whether folic acid directly prevents bone loss or acts via its homocysteine lowering effect. This needs to be clarified in the next studies.

Prevention of bone loss and hyperhomocysteinemia by folic acid supplements in the present study are consistent with previous studies $[62,63]$ which stated that the serum homocysteine level is inversely associated with folate level, 
Zidan et al. Journal of Histology \& Histopathology 2015,

and that folate supplements therapy can lower homocysteine level effectively.

Previous data suggested a role of folic acid in modulating the expression of the redox enzymes (Trx-1/NOX-4) disrupted by increased levels of HCY. These results also suggested that folic acid alleviates the oxidative stress [37].

\section{Conclusion}

The results of this study showed that hyperhomocysteinemia induced marked structural changes in the epiphyseal plate, trabecular and cortical bone of femur in young rats. These changes confirmed the association between increased homocysteine level and fracture risk. The suggested mechanism for these changes could be related to decreased osteoprotegerin expression as proved in our work.

Moreover, folic acid provided significant protection against bone changes induced by increased homocysteine levels. However, it is not clear whether folic acid directly prevents bone loss or acts via its homocysteine lowering effect. We recommend further research to clarify this point in the next studies. In addition, future research studies are needed to evaluate the potential clinical utility of folic acid as a therapeutic agent to prevent osteoporosis associated with hyperhomocysteinemia.

\section{Competing interests}

The authors declare that they have no competing interests.

\section{Authors' contributions}

\begin{tabular}{|l|c|c|}
\hline Authors' contributions & RAZ & HMV \\
\hline Research concept and design & $\checkmark$ & $\checkmark$ \\
\hline Collection and/or assembly of data & $\checkmark$ & $\checkmark$ \\
\hline Data analysis and interpretation & $\checkmark$ & $\checkmark$ \\
\hline Writing the article & $\checkmark$ & -- \\
\hline Critical revision of the article & -- & $\checkmark$ \\
\hline Final approval of article & -- & $\checkmark$ \\
\hline Statistical analysis & $\checkmark$ & -- \\
\hline
\end{tabular}

\section{Acknowledgement}

We would like to thank Dr. Mona AboElkhair.

For her aid in statistical results.

\section{Publication history}

Editor: Giuseppe Musumeci, University of Catania, Italy.

Received: 27-Apr-2015 Final Revised: 02-Jun-2015

Accepted: 08-Jun-2015 Published: 18-Jun-2015

\section{References}

1. Ray NF, Chan JK, Thamer M and Melton LJ, 3rd. Medical expenditures for the treatment of osteoporotic fractures in the United States in 1995: report from the National Osteoporosis Foundation. J Bone Miner Res. 1997; 12:24-35. | Article | PubMed

2. Center JR, Nguyen TV, Schneider D, Sambrook PN and Eisman JA. Mortality after all major types of osteoporotic fracture in men and women: an observational study. Lancet. 1999; 353:878-82. | Article | PubMed

3. Melton LJ, 3rd. Adverse outcomes of osteoporotic fractures in the general population. J Bone Miner Res. 2003; 18:1139-41. | Article | PubMed

4. van Meurs JB, Dhonukshe-Rutten RA, Pluijm SM, van der Klift M, de Jonge R, Lindemans J, de Groot LC, Hofman A, Witteman JC, van Leeuwen JP, Breteler MM, Lips P, Pols HA and Uitterlinden AG. Homocysteine levels and the risk of osteoporotic fracture. N Engl J Med. 2004; 350:2033-41.] | Article | PubMed

5. Aubin JE, Liu F, Malaval L and Gupta AK. Osteoblast and chondroblast differentiation. Bone. 1995; 17:77S-83S. | Article | PubMed

6. McLean R.R, Jacques P.F, Selhub J, Tucker K.L, Samelson E.J, Broe K.E and Kiel D.P. Homocysteine as a predictive factor for hip fracture in older persons. N Engl J Med. 2004; 350:2042-2049. | Article

7. Sakamoto W, Fujie K, Isomura S, Kaga M, Kohgo T, Yamada N and Nishihira J. Secretion of macrophage migration inhibitory factor differs from interleukin-6 in hydrogen peroxide- and LPS-stimulated human fibroblasts. Int Immunopharmacol. 2002; 2:1123-31. | Article | PubMed

8. Cagnacci A, Baldassari F, Rivolta G, Arangino $S$ and Volpe A. Relation of homocysteine, folate, and vitamin B12 to bone mineral density of postmenopausal women. Bone. 2003; 33:956-9. | Article | PubMed

9. Bucciarelli P, Martini G, Martinelli I, Ceccarelli E, Gennari L, Bader $R$, Valenti R, Franci B, Nuti R and Mannucci PM. The relationship between plasma homocysteine levels and bone mineral density in post-menopausal women. Eur J Intern Med. 2010; 21:301-5. | Article | PubMed

10. Roblin X, Phelip JM, Genevois M, Ducros V and Bonaz B. Hyperhomocysteinaemia is associated with osteoporosis in patients with Crohn's disease. Aliment Pharmacol Ther. 2007; 25:797-804. | Article I PubMed

11. Biagini MR, Tozzi A, Bongini E, Capanni M, Galli A, Milani S and Surrenti C. Association of plasma homocysteine with bone mineral density in postmenopausal women with osteoporosis or osteopenia affected by primary biliary cirrhosis. J Clin Gastroenterol. 2007; 41:635. | Article | PubMed

12. Alley RA, Chen EL, Beyer TD and Prinz RA. Does homocysteine contribute to bone disease in hyperparathyroidism? Am J Surg. 2008; 195:374-7. | Article | PubMed

13. Seshadri S, Beiser A, Selhub J, Jacques PF, Rosenberg IH, D'Agostino RB, Wilson PW and Wolf PA. Plasma homocysteine as a risk factor for dementia and Alzheimer's disease. N Engl J Med. 2002; 346:476-83. | Article I PubMed

14. Azizi ZA, Zamani A, Omrani LR, Omrani L, Dabaghmanesh $\mathrm{MH}$, Mohammadi A, Namavar MR and Omrani GR. Effects of hyperhomocysteinemia during the gestational period on ossification in rat embryo. Bone. 2010; 46:1344-8. | Article | PubMed

15. McLean RR, Jacques PF, Selhub J, Fredman L, Tucker KL, Samelson EJ, Kiel DP, Cupples LA and Hannan MT. Plasma B vitamins, homocysteine, and their relation with bone loss and hip fracture in elderly men and women. J Clin Endocrinol Metab. 2008; 93:2206-12. | Article | PubMed Abstract | PubMed Full Text

16. Dhonukshe-Rutten RA, Pluijm SM, de Groot LC, Lips P, Smit JH and van Staveren WA. Homocysteine and vitamin B12 status relate to bone turnover markers, broadband ultrasound attenuation, and fractures in healthy elderly people. J Bone Miner Res. 2005; 20:921-9. | Article | PubMed

17. Eberhardt RT, Forgione MA, Cap A, Leopold JA, Rudd MA, Trolliet M, Heydrick S, Stark R, Klings ES, Moldovan NI, Yaghoubi M, GoldschmidtClermont PJ, Farber HW, Cohen R and Loscalzo J. Endothelial dysfunction in a murine model of mild hyperhomocyst(e)inemia. J Clin Invest. 2000; 106:483-91. | Article | PubMed Abstract | PubMed Full Text

18. Dworakowski $R$, Anilkumar $N$, Zhang $M$ and Shah AM. Redox signalling involving NADPH oxidase-derived reactive oxygen species. Biochem Soc Trans. 2006; 34:960-4. | Article | PubMed

19. Satta E, Perna A.F, Lombardi C, Acanfora F, Violetti E, Romano M.M, Capasso R, Pisano M, Paduano F and De Santo N.G. Hyperhomocyteinemia in chronic renal failure. G. Ital. Nefrol. 2006; 23:480-489. | Article

20. Golbahar J, Hamidi A, Aminzadeh MA and Omrani GR. Association 
of plasma folate, plasma total homocysteine, but not methylenetetrahydrofolate reductase C667T polymorphism, with bone mineral density in postmenopausal Iranian women: a cross-sectional study. Bone. 2004; 35:760-5. I Article I PubMed

21. Morris MS, Jacques PF and Selhub J. Relation between homocysteine and B-vitamin status indicators and bone mineral density in older Americans. Bone. 2005; 37:234-42. | Article | PubMed

22. Stead LM, Brosnan ME and Brosnan JT. Characterization of homocysteine metabolism in the rat liver. Biochem J. 2000; 350 Pt 3:685-92. | Article | PubMed Abstract | PubMed Full Text

23. Boushey CJ, Beresford SA, Omenn GS and Motulsky AG. A quantitative assessment of plasma homocysteine as a risk factor for vascular disease. Probable benefits of increasing folic acid intakes. JAMA. 1995; 274:1049-57. | Article | PubMed

24. Sato Y, Honda Y, Iwamoto J, Kanoko T and Satoh K. Effect of folate and mecobalamin on hip fractures in patients with stroke: a randomized controlled trial. JAMA. 2005; 293:1082-8. | Article | PubMed

25. Woo KS, Chook P, Lolin YI, Sanderson JE, Metreweli C and Celermajer DS. Folic acid improves arterial endothelial function in adults with hyperhomocystinemia. J Am Coll Cardiol. 1999; 34:2002-6. | Article | PubMed

26. Herrmann M, Taban-Shomal O, Muller S, Gunter L, Hubner U, Bohm $M$ and Herrmann W. Hyperhomocysteinemia--the biochemical link between a weak heart and brittle bones? Clin Lab. 2006; 52:137-47. PubMed

27. Matte C, Scherer EB, Stefanello FM, Barschak AG, Vargas CR, Netto CA and Wyse AT. Concurrent folate treatment prevents $\mathrm{Na}+, \mathrm{K}+-\mathrm{ATPase}$ activity inhibition and memory impairments caused by chronic hyperhomocysteinemia during rat development. Int J Dev Neurosci. 2007; 25:545-52. | Article | PubMed

28. Bazzano LA. Folic acid supplementation and cardiovascular disease: the state of the art. Am J Med Sci. 2009; 338:48-9. I Article I PubMed

29. Zhu X, Smith MA, Honda K, Aliev G, Moreira PI, Nunomura A, Casadesus G, Harris PL, Siedlak SL and Perry G. Vascular oxidative stress in Alzheimer disease. J Neurol Sci. 2007; 257:240-6. I Article I PubMed Abstract | PubMed Full Text

30. Gerdhem P, Ivaska KK, Isaksson A, Pettersson K, Vaananen HK, Obrant KJ and Akesson K. Associations between homocysteine, bone turnover, BMD, mortality, and fracture risk in elderly women. J Bone Miner Res. 2007; 22:127-34. | Article | PubMed

31. Boyce BF and Xing L. Biology of RANK, RANKL, and osteoprotegerin. Arthritis Res Ther. 2007; 9 Suppl 1:S1. | Article | PubMed Abstract | PubMed Full Text

32. Hofbauer LC and Schoppet M. Clinical implications of the osteoprotegerin/RANKL/RANK system for bone and vascular diseases. JAMA. 2004; 292:490-5. | Article | PubMed

33. Boyce BF and Xing L. Functions of RANKL/RANK/OPG in bone modeling and remodeling. Arch Biochem Biophys. 2008; 473:139-46. | Article | PubMed Abstract | PubMed Full Text

34. Institute of Laboratory Animal Resources. Guide for the Care and Use of Laboratory Animals. National Academy Press. Washington, DC. 1996

35. Ajeigbe KO, Olaleye SB, Oladejo EO and Olayanju AO. Effect of folic acid supplementation on oxidative gastric mucosa damage and acid secretory response in the rat. Indian J Pharmacol. 2011; 43:578-81. | Article | PubMed Abstract | PubMed Full Text

36. Masse PG, Boskey AL, Ziv I, Hauschka P, Donovan SM, Howell DS and Cole DE. Chemical and biomechanical characterization of hyperhomocysteinemic bone disease in an animal model. BMC Musculoskelet Disord. 2003; 4:2. | Article | PubMed Abstract | PubMed Full Text

37. Tyagi N, Kandel M, Munjal C, Qipshidze N, Vacek JC, Pushpakumar SB Metreveli $\mathrm{N}$ and Tyagi SC. Homocysteine mediated decrease in bone blood flow and remodeling: role of folic acid. J Orthop Res. 2011; 29:1511-6. | Article | PubMed Abstract | PubMed Full Text

38. Waynforth HB. Experimental and surgical techniques in the rat. London: Academic Press. 1980.
39. Bancroft JD and Gamble M. Theory and practice of histological techniques. 6th ed. London, NewYork, Philadelphia: Churchill Livingstone. 2008

40. Cross SS, Yang Z, Brown NJ, Balasubramanian SP, Evans CA, Woodward JK, Neville-Webbe HL, Lippitt JM, Reed MW, Coleman RE and Holen I. Osteoprotegerin (OPG)--a potential new role in the regulation of endothelial cell phenotype and tumour angiogenesis? Int J Cancer. 2006; 118:1901-8. | Article | PubMed

41. Hofbauer LC and Heufelder AE. Clinical review 114: hot topic. The role of receptor activator of nuclear factor-kappaB ligand and osteoprotegerin in the pathogenesis and treatment of metabolic bone diseases. J Clin Endocrinol Metab. 2000; 85:2355-63. | Article | PubMed

42. Silvestrini G, Ballanti P, Patacchioli F, Leopizzi M, Gualtieri N, Monnazzi $P$, Tremante E, Sardella D and Bonucci E. Detection of osteoprotegerin (OPG) and its ligand (RANKL) mRNA and protein in femur and tibia of the rat. J Mol Histol. 2005; 36:59-67. | Article I PubMed

43. Singh D. Principle and Techniques. In Histology, Microscopy and Photography., 2003. 1st ed., CBS Puplishers and Distributers. New Delhy, Bangalore (India). 2003; 679-699.

44. Surve VV, Andersson N, Lehto-Axtelius D and Hakanson R. Comparison of osteopenia after gastrectomy, ovariectomy and prednisolone treatment in the young female rat. Acta Orthop Scand. 2001; 72:525-32. | Article | PubMed

45. Balena R, Toolan BC, Shea M, Markatos A, Myers ER, Lee SC, Opas $E E$, Seedor JG, Klein H, Frankenfield D and et al. The effects of 2-year treatment with the aminobisphosphonate alendronate on bone metabolism, bone histomorphometry, and bone strength in ovariectomized nonhuman primates. J Clin Invest. 1993; 92:2577-86. I Article | PubMed Abstract | PubMed Full Text

46. Sato Y, Iwamoto J, Kanoko T and Satoh K. Homocysteine as a predictive factor for hip fracture in elderly women with Parkinson's disease. Am J Med. 2005; 118:1250-5. | Article | PubMed

47. Gerdhem P, Ivaska KK, Alatalo SL, Halleen JM, Hellman J, Isaksson A Pettersson K, Vaananen HK, Akesson K and Obrant KJ. Biochemical markers of bone metabolism and prediction of fracture in elderly women. J Bone Miner Res. 2004; 19:386-93. I Article I PubMed

48. Lane NE, Yao W, Kinney JH, Modin G, Balooch M and Wronski TJ. Both hPTH(1-34) and bFGF increase trabecular bone mass in osteopenic rats but they have different effects on trabecular bone architecture. J Bone Miner Res. 2003; 18:2105-15. | Article | PubMed

49. Nonaka H, Tsujino T, Watari Y, Emoto N and Yokoyama M. Taurine prevents the decrease in expression and secretion of extracellular superoxide dismutase induced by homocysteine: amelioration of homocysteine-induced endoplasmic reticulum stress by taurine. Circulation. 2001; 104:1165-70. | Article | PubMed

50. Zhang Q, Zeng X, Guo J and Wang X. Effects of homocysteine on murine splenic $B$ lymphocyte proliferation and its signal transduction mechanism. Cardiovasc Res. 2001; 52:328-36. | Article I PubMed

51. Zhang $Q$, Zeng $X$, Guo J and Wang $X$. Oxidant stress mechanism of homocysteine potentiating Con A-induced proliferation in murine splenic T Iymphocytes. Cardiovasc Res. 2002; 53:1035-42. | Article | PubMed

52. Pei L and Tontonoz P. Fat's loss is bone's gain. J Clin Invest. 2004; 113:805-6. | Article | PubMed Abstract | PubMed Full Text

53. Ng A and Duque G. Osteoporosis as a lipotoxic disease. IBMS BoneKEy. 2010; 7:108-123. | Article

54. Khan M, Yamauchi M, Srisawasdi S, Stiner D, Doty S, Paschalis EP and Boskey AL. Homocysteine decreases chondrocyte-mediated matrix mineralization in differentiating chick limb-bud mesenchymal cell micro-mass cultures. Bone. 2001; 28:387-98. | Article | PubMed

55. Lubec B, Fang-Kircher S, Lubec T, Blom HJ and Boers GH. Evidence for McKusick's hypothesis of deficient collagen cross-linking in patients with homocystinuria. Biochim Biophys Acta. 1996; 1315:159-62. | Article I PubMed

56. Sakamoto W, Isomura H, Fujie K, Deyama Y, Kato A, Nishihira J and Izumi $\mathrm{H}$. Homocysteine attenuates the expression of osteocalcin but enhances osteopontin in MC3T3-E1 preosteoblastic cells. Biochim Biophys Acta. 
Zidan et al. Journal of Histology \& Histopathology 2015,

http://www.hoajonline.com/journals/pdf/2055-091X-2-16.pdf

2005; 1740:12-6. | Article | PubMed

57. Herrmann M, Widmann T, Colaianni G, Colucci S, Zallone A and Herrmann W. Increased osteoclast activity in the presence of increased homocysteine concentrations. Clin Chem. 2005; 51:2348-53. | Article | PubMed

58. Simonet WS, Lacey DL, Dunstan CR, Kelley M, Chang MS, Luthy R, Nguyen $H Q$, Wooden S, Bennett L and Boone T et al. Osteoprotegerin: a novel secreted protein involved in the regulation of bone density. Cell. 1997; 89:309-19. | Article | PubMed

59. Bucay N, Sarosi I, Dunstan CR, Morony S, Tarpley J, Capparelli C, Scully S, Tan HL, Xu W, Lacey DL, Boyle WJ and Simonet WS. osteoprotegerindeficient mice develop early onset osteoporosis and arterial calcification. Genes Dev. 1998; 12:1260-8. | Article | PubMed Abstract | PubMed Full Text

60. Yamazaki $\mathrm{H}$ and Sasaki T. Effects of osteoprotegerin administration on osteoclast differentiation and trabecular bone structure in osteoprotegerin-deficient mice. J Electron Microsc (Tokyo). 2005; 54:467-77. | Article | PubMed

61. Gruber HE and Rude RK. Alterations in osteoclast morphology following osteoprotegerin administration in the magnesium-deficient mouse. Biotech Histochem. 2003; 78:231-6. | Article | PubMed

62. Manolagas SC. Birth and death of bone cells: basic regulatory mechanisms and implications for the pathogenesis and treatment of osteoporosis. Endocr Rev. 2000; 21:115-37. | Article | PubMed

63. Claes L, Schmalenbach J, Herrmann M, Olku I, Garcia P, Histing T, Obeid $\mathrm{R}$, Schorr H, Herrmann W, Pohlemann T, Menger MD and Holstein JH. Hyperhomocysteinemia is associated with impaired fracture healing in mice. Calcif Tissue Int. 2009; 85:17-21. | Article | PubMed

\section{Citation:}

Zidan RA and Elnegris HM. Effect of homocysteine on the histological structure of femur in young male albino rats and the possible protective role of folic acid. J Histol Histopathol. 2015; 2:16.

http://dx.doi.org/10.7243/2055-091X-2-16 